\title{
Vergiftiging in antieke Rome
}

\author{
F.P. Retief \\ Navorsingsgenoot, Universitcit van dic Vrystaat, Posbus 339, Blocmlontcin, 9300 \\ E-pos: retieff@rs.uovs.ac.za
}

L. Cilliers

Departement Engels en Klassieke Kultuur, Universiteit van die Vrystaat, Posbus 339, Bloemlontein, 9300)

E-pos: fglc@rs.uovs.ac.za

Ontvang 6 Julie 1999; annvaar // September 1999

\section{UITTREKSEL}

Die voorkoms van vergiftiging in antieke Rome word behandel. Die eerste insident aangeteken was in .33/ v.C. 10e 170 vone skuldig bevind is aan massa-vergiftiging ten tye van 'n ernstige epidemie. Hierna was daar 'n tocname in die voorkoms. van kwaadwillige vergiftiging, wat tydens die Julii-Claudiese dinastie, en Nero se heerskappy in besonder; 'n piek bereik het. Gif-selfinoord was seldsalam. alloewel Plinius die Onere gif-genadedood by bejaardes en siekes (wat daarvoor vra) goedgekeur het. 'u Groot verskeidenheid gifstowwe van plantaardige, dierlike en mineraal-oorsprong is deur Dioscorides, Scribonius Largus, Plinius die Oucre. Nicander, Galenus en andere beskryf. Plantaardige giwwe was die beste bekend en oënskynlik die meeste gebruik. Dierlike giwwe was grotendeels gebaseer op bygeloof (en in werklikheid skadeloos), en mineraalgifstowwe oorwegend onbeproef en min gebruik. Gifstowi'e deur. historici aan spesifieke vergiftigingsepisodes gekoppel, sluit in akonitum (monnikskap; "stiefma se gif", baie populê; vinnig. e"n dodelik in klein dosisse), dollekerwel ('hemlock'), taksus-ekstrak en 'seehats' ('n onbekende seedier). Professionele vergiftigers soos Canidia, Locusta en Martina sou wel 'n kombinasie van giwwe gebruik het. In 'n sosiale kultunr gekenmerk deur bygelowigheid en waar onkunde die wetenskaplike opsporing van vergiftiging onmoontlik gemaak het, is dit waarskynlik dat vele misdadigers ongestraf' gegaan het terwyl onskuldiges veroordeel is. Toevallige vergiftiging weens giftige voorskrifte deur onkundige terapeute w'as v'ermoedelik 'n algemene verskynsel.

\section{Abstract \\ Poisoning in ancient Rome}

Recorded instances of poisoning in ancient Rome were studied. The first such event was in 331 BC when, concurrent with a serious epidemic, 170 women were found guilty of mass poisoning. Historians reported a subsequent increase in deliberate poisoning, which appeared to reach an alarming peak during the Julio-Claudian dynasty and the reign of Nero in particular: Suicide by poison w'as rare, but Pliny the Elder condoned euthanasia in the elderly and infirm when so requested. A large number of poisonous substances of plant, animal and mineral origin were described by Dioscorides, Scribonius Largus, Pliny the Elder; Nicander, Galen and others. Of Ihese' the plant materials were studied in the greatest detail, the animal materials were largely fictitious, and the mineral toxins w'ere least understood and rarely used for deliberate poisoning. Poisons found to be actually mentioned by name include aconite ("stepmother's poison", very popular; and rapidly lethal in small doses), hemlock, Yew extract and "sea hare" (unknown marine animal); professional poisoners like Canidia, Locusta and Martina may well have used a combination of poisons. In a culture of high superstition when scientific ignorance made the detection of poisoning virtually impossible, it is likely that many poisoners went unpunished. whilst innocent persons were wrongly condemned. Inadvertent poisoning through medicaments prescribed by ignoramt professionals was probably common.

\section{INLEIDING}

Ons begrip oor die werking en gebruik van gifstowwe wat terugdateer na prehistoriese tye, verbreed met die ontstaan van geskrewe rekords. Hicruit leer ons dat die oerbeskawings van Egipte, Mesopotamië, Indië en China 5000 jaar gelede reeds vertroud was met 'n verskeidenheid gifstowwe, alhoewel dit dikwels problematies is om hierdie substanse in terme van tans bekende giwwe te identifiseer. 'Menes, die eerste farao aan ons bekend (ongeveer 3000 v.C.), het 'n studie gemaak van giftige plante, en hierdie belangstelling is deur opeenvolgende farao's voortgesit tot en met die laaste regeerder, Kleopatra, wat in 30 v.C. gesterf het, moontlik as gevolg van gif-sclfmoord. ${ }^{2}$ Persiesc heersers het van gifstowwe gebruik gemaak. ${ }^{3}$ In die Griekse mitologie is daar talle verwysings na gifmoord, en teen die $4 \mathrm{dc}$ eeu v.C. is gif in Athene gebruik vir geregtelike teregstellings. Sokrates is byvoorbeeld verplig om dollekerwel ("hemlock") te drink.'

Die aard en voorkoms van vergiftiging tydens die Romeinse era vanat die vroeë Republick (4de eeu v.C.) tol $\mathrm{en} \mathrm{meı} \mathrm{dic}$ Keiserryk van die 3 de eeu $n$ C. is nagespoor en word hieronder weergegec en bespreck.

\section{INSIDENTE VAN VERGIFTIGING}

2.1 Vergiftiging in die Republikeinse era (ode eeu v.C. 27 v.C.)

Tydens die Romeinse Keiserryk, en die Julii-Claudiese dinastic (Augustus, Tiberius, Caligula, Claudius en Nero) in besonder, het vergiftiging algemeen voorgekom. Terwyl selfmoord relaticl seldsaam was, is dit interessant dat Plinius ${ }^{\dagger}$ tog die gebruik van gepaste middels om cutanasie by fisies of psigies algetakelde persone te bewerkstellig, gepropagecr het (Naturalis //istoria ii. 156; xx. 197). In die ecrste ceu n.C., en tydens dic heerskappy van Nero in besonder, het gifmoord sulke afmetings alangeneem dat die satirikus Juvenalis' die sosiale moraliteit van verval in die hoër stand skerp veroordecl hel. Ten cincle status te hê, so 
het liy beweer, moes jy aandadig gewees hel alan een of ander ernstige wandaad, en rykdom het dikwels voortgevloei uit misdaad (Sarie i. 73-76). Hy het verwys na 'n persoon wat welgesteld geraak het nadat hy ses familielede met akonitum vergiftig het (Satire i. 158), asook na Pontia wat by haar vriendinne gespog het oor halar vermoce om gaste net vergiltigde kos te vermoor (Satire vi. 638-640). Dit hel vir vroue aanvaarde praktyk geword om stiefkinders te vergiftig (Satire vi. 627), en bejaarde vaders is gewaarsku om voor clke ete teëmiddels teen gif in te neem (Satire xiv. 250-251). Alhoewel hierdic opmerkings in die konteks van 'n satire voorkom, moes dit 'n element van waarheid bevat het om as verwysings na aktuele wantoestande herkenbaar te wees.

Die eerste gerapportecrde insident van gilmisdaad in Rome kan vernoedelik teruggevoer word na 331 v.C. 'n Ernstige pestilensie het die stad getref, maar 'n gerug het ook ontstian dat die hoë mortaliteit decls aan vergiftiging te wyte was. Alhoewel die geskiedskrywer Livius" nie heeltemal oorluig was van die geldigheid van hierdie aanklag nie, vermeld hy dic verhaal van 'n diensmeisie wat die kurule aedile, Maximus, ingelig het dat sy bereid was om ' $n$ gilkomplot te openbaar mits haar cie veiligheid gewaarborg word. Die Senaat het haar hierdie versekering gegee en sy het toe vertel dat die getroude vroue van Rome saamgesweer het om op groot skaal gifmoord te pleeg. Sy het vervolgens die konsuls na vroue geneem wat na bewering besig was om gifmengsels te brou en ook gilstore uitgewys. Twintig gesiene vroue wat hicrna in die Forum verhoor is, het egter beweer dat hulle helende preparate en nie giwwe nic, vervaardig het. Toc hulle versock is om hul gifmengsels self te drink, het hulle toestemming gevra om hieroor te besin, maar spoedig teruggekeer, die mengsels ingeneem en almal gesterf. Verdere arrestasies en verhore het gevolg, en uiteindelik is 170 vroue skuldig bevind en met die dood gestraf. Hierdie episode, dic eerste van sy soort in Rome, is as 'n baic crnstige voorbode gesien, en na indringende besinning is 'n spyker deur' $n$ diktator in 'n muur gedryf ten einde verdere skuldiges van hul boosheid te genees - waarskynlik as 'n soort simpaliese magie (Livius viii. 18). Dic moontlikheid is ook nic uitgesluit nic dat die teregstelling van die vroue bedoel was as 'n socnoffer om dic pes te beëindig.

Tydens die Tweede Puniese Oorlog het Capua onder Virrius teen Rome gerebelieer in die hoop dat Hannibal hulle tot hulp sou snel. Dit hel nie gebeur nie, en na' $n$ beleëring is die stad in 211 v.C. deur Rome ingeneem. In die wete dat geen genade verwag kan word nic, het Virrius die leierskorps en senatore probecr oorreed om saam met hom selfmoord te pleeg. Sewe en twintig van die taglig senatore het ingestem en Virrius na sy woning gevolg. Hier is 'n maaltyd voorgesit, gesellig saam verkeer en heelwat wyn gedrink, waarna almal gif ingeneem het. Op roerende wyse is van mekaar afskeid geneem; sommige het in Virrius se woning gebly en ander het huiswaarts gekeer. Moontlik weens dic groot maaltyd wat vooralgegaan het, het die gif stadig gewerk, maar toe die Romeine die volgende oggend die slad binnekom, was almal wel dood. Die drie en vyftig oorlewende senatore is deur die Romeine om die lewe gebring (Livius xxvi. 13-14).

Teen die einde van die Tweede Puniese Oorlog het die Romeinse generaal, Scipio, in 203 v.C. die Numidiese koning, Syphax ('n bondgenoot van Kartago), in Noord-Afrika verslaan. Syphax se vrou, Sophonisba (dogter van die Kartaagse leier, Hasdrubal), het 'n verhouding aangeknoop met Masinissa, 'n generaal van Scipio en seun van 'n Numidiese koning wat deur Syphax ontroon is en toe 'n Romeinse bondgenoot geword het. In 'n desperate poging om sy geliefde te red van Romeinse gevangenisskap, trou Masinissa toc met Sophonisba. Onmid- dellik na die seremonic word Masinissal egter deur Scipio gewarsku dat hierdie daad nic halar lot kon verander nie. Verbitterd gaan Masinissa na sy tent, berei die gifmengsel wat alle konings vir noodgeleenthede byderhand gehou hel. en stuur dit na Sophonisba met die hoodskap dat sy bevelhebher hom beroof het van die vermoë om die eerste belofte wat 'n bruidegom sy bruid skuld, na te kom. maar dat hy nou sy ansler belotie aan haar gestand doen, naamlik om haar die geleentheie te bied om Romeinse gevangenisskap vry te spring. Sy drink die beker, en in 'n laaste boodskap aan Masinissa spreck sy begrip uit vir sy posisie, maar rou oor die ironie dal halar onvoltooide huwelik en begrainis op dieselfde dag plaasvind (Livius $x \times x .12-15)$.

Livius (xxxix.41) vermeld dat Rome en omgewing in 184 v.C. weer getref is deur 'n vermoede van grootskaalse vergitiging, wat salamgeval het met 'n sameswering van skalapwagters en Bacchanaliese aktiwiteile. Uitgehreide ondersoeke het daartoe gelei dal ongeveer 2000 persone skuldig bevind en op verskeic wyses gestral is. In 180 v.C. is Rome deur 'n epidemie getref en weer was daar alanklagte van massavergiftiging. Hostilia, die vrou van 'n konsul, is op omstandigheidsgetuienis skuldig bevind en saam mel 300() persone tereggestel (Livius xl. $37 \mathrm{en} \mathrm{43).}$

In 154 v.C. word twee voormalige konsuls deur hul vroue mel gif vermoor; volgens Livius (Epitomae 48) ralk dit duidelik dat vergitiging nou besig was om in Rome 'n ernstige euwel le word.' Die Senaat het direkte jurisdiksie verkry oor alle misdaad wal 'n openbare ondersock benodig hel, soos verraad, sameswerings, sluipmoord en vergiftiging (Polybius' vi. 13.4). Cato het by geleentheid soos volg gereagecr Icenoor 'n tribuun wat van vergiftiging verdink is en toe 'n swak wet wou deurvoer: "Jongman, ek weet nic wat die ergste is nic - om jou mengsels te drink of jou welle te hevorder nie" (Plutarchus." P/ut. ix. 7). Cato het sell ook die mening uitgespreek dat alle owerspelige vroue polensiële gifmoordenaars was (Quintilianus" v. 11.39). Teen die einde van die tweede eeu v.C. was daar ook reeds 'n hof wat spesifick gifsake hanteer het. ${ }^{10} \mathrm{en}$ in 80 v.C. promulgeer dic diklator Sulla 'n stel wette oor giwwe en gifmoord." 'n Persoon sou skuldig wees indien hy gevaarlike middels gemaak. verkoop ol besit het met die doel om moord le plecg. Quintilianus (ix. 2.105) sou later aanvoer dat die permanente verminking van 'n persoon deur toediening van gif' netso ernstig was as moord. Cicero se hofredes getuig ook van 'n hoë voorkoms van vergiftiging in die gemeenskap van sy tyd. Hy verwys byvoorbeeld na Oppianicus wat sy vrou, sy broer en sy swanger skoonsuster vergiftig hel ten einde ryk te erf ( $P r o C_{\text {Cluentio }}{ }^{12}$ 30-31). Fabricius wal 'n vriend wou vergiftig ( $P_{r o}$ Cluchtio 47), Domitius wat sy neef vermoor hel (Philippicae ${ }^{13} \times$ i. 6.13). en Catilina wat aan gifmoord skuldig was (/n Catilinem ${ }^{14}$ ii. 4.7). Ons weet ook van die Britse koning, Catuvoleus, wal selfmoord mel taksus ("yew")-gif" verkies het bo oorgawe an dic Romeine. ${ }^{15}$

Plinius (xxi. 12) vertel dat Marcus Antonius voor die slag van Aclium (31 v.C.) so agterdoglig jeens Kleopatra was dat hy geen kos van haar aanvaar het tensy dit vooral deur sy persoonlike proewer getoets is nie. Om haar deskundigheid te toon, het sy by geleentheid wel daarin geslaag om 'n vergiligde beker verby die amptelike proewer te smokkel, maar Antonius op die laisle oomblik gekeer het om dit te drink omdat sy hom liefgehad het. Dié drankie het hierna 'n prisonier onmiddellik gedood. Plutarchus (Amtonius 86) is verantwoordelik vir die populêre oorlewering dat Kleopatra selfinoord gepleeg hel deur die byt van 'n adder, maar 'n goeic saak is uitgemaik dal sy git gedrink het.'

Octavianus, oorwinnaar by Actium, het vier jaar later as 
Augustus die eerste heerser van die Romeinse Keiserryk geword - en sluit die Republikeinse cra af.

\subsection{Vergiftiging in die Romeinse Keiserryk (27 v.C. - 5de eeu n.C.)}

Voorbeelde van vergittiging sal kronologies hanteer word, telkens gekoppel an die heersende keiser. Die Julii-Claudiese dinastic (27 v.C. -68 n.C.) was veral berug vir herhalende episodes van gifmoord.

\section{Augustus ( 27 v.C. -14 n.C.)}

Die vrou van hicrdic uitstande grondlegger van die Romeinse Keiserryk, Livia, is volgens dic geskiedskrywers Tacilus ${ }^{16}$ (Annales i.3.3) en Dio Cassius ${ }^{17}$ (lvi.30.2) daarvan verdink dat sy Augustus se kleinkinders (Lucius en Gaius) mel gil vermoor hel (Tacitus, Ammales i. 3.3; Dio Cassius Ivi. 30.2). Daar is ook beweer dat sy die sick en bejalarde Augustus eventueel met vergiftigde vye uit die wêreld gehelp het (Dio Cassius lvi. 30; Tacitus, Ammales i. 5.1-3), maar dié gerug kan nie gestaal word nie en is heel waarskynlik onwalar. Dic keiser se protégé, die digter Horatius, ${ }^{18}$ vertel verder van die gevreesde Canidia wat verskeic persone vergittig het, onder andere ene Albucius en moontlik haar eic mocder deur gebruik te malak van 'n mengsel van heuning en dollekerwel (Satire ii. 1.56). In hicrdic tyd is ' $n$ vriend van Augustus, Nonus Asprenas, volgens Plinius (xxxv. 164) en Suctonius" (A ugustus 56) in die Senalal daarvan beskuldig dat hy 130 gaste tydens 'n eetmat vergiftig het. Ene Apollodorus, 'n redenaar van Pergamon, is skuldig bevind op dric aanklagte van gilmoord, maar vlug na Massilia en stig 'n skool (Seneca,," Controversiae ii. 13.13).

\section{Tiberius (14-37 n.C.)}

Kort nal sy troonsbestyging het 'n opperhoof uit Germanie, Adzandestrius, in 'n brief aan die keiser alangebied om Rome se gedugte opponent, die Germaanse leier Arminius, om die lewe te bring mits dic Romeine hom voorsien van 'n geskikte gifstof. 'n Verontwaardigde Tibcrius het geantwoord dat Rome nie sy vyande op onderduimse wyse beveg nic maar deur openlike militêre konfrontasic (Tacitus, Annales xi. 88).

In 19 n.C. sterf Germanicus, populêre militêre bevelvoerder en broerskind van Tiberius, onder suspisieuse omstandighede in Klein-Asië, nal 'n struweling mel die goewerneur, Piso, en sy vrou, Plancina. Germanicus se vriende en sy vrou, Agrippina, beweer dat hy vergiftig is deur Piso met die samewerking van 'n berugte gifvervaardiger, Martina ('n vertroucling van Plancina). Die saak word na die Senaat in Rome verwys, maar onderweg sterf Martina onverwags en 'n gitmonster word in een van haar haarlokke versteek gevind. Tydens die verhoor was daar openbare steun vir Germanicus se familie. Gilmoord kon nie bewys word nie, maar weens openbare alkeur pleeg Piso tog selfmoord (Tacilus, Annales iii. 7.12-15). Suetonius (Tiberius 53. 1) beweer dat Agrippina tydens die verhoor vermoed het dat die keiser (wat goed bevriend was met Piso) haar wou vergiftig, en dat Tiberius haar vrees uitgebuit het.

Tacitus (Amnales iii. 21-25) skryf van die verhoor van 'n adellike vrou, Lepida, wat daarvan aangekla is dat sy ontrou was aan haar bejaarde man en hom probeer vergilitig het. Na marteling het 'n slavin getuig dat Lepida wel skuldig was, en is sy lewenslank verban. In hierdic tyd het Tiberius toegelaat dat massaverhore plaasvind van persone wat aangekla is van maiestas, oltewel die skending van die Stat of die keiser se waardigheid. Vele onskuldige veroordelings het tot wydverspreide onrustigheid gelei - en Tacilus (Amnales vi. 40) vertel van die gesiene senator. Vibulenus Agrippa, wat by die aanhoor van sy klagstaat in die senaat, in alanvaarding dat hy veroordeel sou word, versicekte gif uit die voue vall sy logil gehial het en voor almal selfmoord geplecg het.

In 23 n.C. het Drusus, Tiberius se seun. in opstind gekom Icen Sejanus, die prefek van die Practoriese Wag, wall ook die minnaar van sy vrou, Livilla, was. Met halar samewerking hel Sejanus toe' 'n gif mel verlengde aksie voorberei, wat die indruk van' 'n kroniese sickte sou skep. Die gif' is witarskynlik deur die eunug, Lygdus, toegedien, en na 'n lang siekbed is Drusus. oorlede. Omdat Tiberius oënskynlik min simpatic mel sy seum se probleme getoon het, is aanvanklik vermoed dat hy die moord beplan het, maar later het Scjanus se vrou, A picata, na marteling die waarheid bevestig (Tacitus, Annales iv. 8: Dio Cassius Ivii. 22; Suctonius, Tiberius 62). Ten cinde die troonopvolging vit homself te probeer bewerkstellig. het Scjanus dit oorweeg om ook Germanicus se seuns met gil te dood (Takitus. Ammales iv. 10), maar Tiberius he ingegryp en almal betrokke hy Drusus se moord opgespoor en tereggestel. In 37 n.C. is Tiberius nil ' lang uitterende sickbed oorlede. Die moontlikheid is genoem dal sy opvolger Gaius (Germanicus se seun) hom kon vergilig hel (Suetonius Tiberius 73), maar hiervoor bestalu min getuienis.

\section{Gaius (Caligula) (37.41 n.C.)}

Ilierdie geestelik versteurde keiser. aan wie kleimtyd die hynalam "Caligula" (=stewelijies) deur sy vader se soldate gegee is, wats vier jaar op die troon voordal hy deur sy lyfwag vermoor is. Hy het gifstowwe versamel en dit sistematies gebruik on sy doelwilte te bereik. Interessant genoeg beweer luvenalis (Satire vi. 610-626) dat Gaius se onstabiliteit ontstan het als gevolg van 'n liefdesdrankic wat sy vrou. Caesonia, alan hom voorgesil hel. Op uitgebreide wyse het hy renperde en joggies vergilitg ten einde by perdewedrenne winste te malak en sy gunstelinge (die sogenaamde Groenspan) te laat wenl. Ook gladiatore is vergiftig om openbare bloedsport na sy wense ic manipuleer. Hy het selis 'n renperd na 'n noenmaal genooi en hom goue hawer gevoer (Dio Cassius lix. 14).

\section{Claudius (41-54 n.C.)}

Aanvanklik beskou as verstandelik vertralig, is hy by verstek aan ander gepaste bloedlyn-kandidate as keiser gekroon. Sy moeder, Antonia, het minagtend na hom verwys ats 'I monster-mens wie se skepping deur die naluur begin malar nooil voltooi is nie. Sy neurologiese afwyking, gekenmerk deur abnormale spraak, emosionele onstabiliteit, geringe tremor en spierspastisiteil (veral regs) en kwyling valn die mond wils feillik sekerlik 'n variant van aangebore serebraalgestremdheid, sonder verstandelike vertraging of epilepsic."1 As keiser was hy onverwags docltreffend. Dio Cassius (lix. 14) vermeld dat hy sy voorganger se gifvoorrald in die see gegooi hel, en dat dit gelei hel lol grootskaalse vrekle vall visse (Suetonius, Gailus 49).

Alhoewel nie bo alle twyled bevestig nie, word algemeen anvaar dat Claudius 'n gifdood gestert het aln dic hand vall sy tweede vrou, Agrippina, om haar seun. Nero. se lroonopvolging te verseker. Josephus ${ }^{22}$ (Bellum ludaicum 20. 8) vermeld slegs 'n gerug van vergiltiging en Plinius se kommentiar is beperk tot die stelling dat 'n komeel waargeneem is in die jaar walain Claudius vergiftig is." Tacitus, Suetonius en Dio Cassius gee effe uileenlopende beskrywings van die insident. Clatudius was toe 65 jaar oud, sicklik en hel baic gedrink. Dil is waltskynlik dat Agrippina die gifmengster, Locusta, genader hel vir" "in gepaste gif wat 'n stadige dood sou veroorsalak sodall vergiftiging nie vermoed sou word nic. Of Nero belrokke was. is onseker. Daar is eenstemmigheid dat Claudius op 13 Oklober 54. die dag van sy dood, 'n priesterlike banket by die Calpitolium bygewoon hel walarna 'n ele by die paleis gevolg hel, en dal die 
eunug, Halotus, aan diens was. Vergiftigde sampioene (eerder as giftige sampiocne) is as die gifmiddel toegedien.

Volgens Dio Cassius (Ixi.34) is Claudius persoonlik tuis deur Agrippina vergiltig. Oënskynlik besope (iets wat dikwels gebeur het), is hy toc uit die banketsaal gedra en het in die loop van die nag gesterf. As voorsorgmaatrël het Agrippina vir Narcissus, die keiser se doeltreflende privalat sekretaris, vroeglydig weggestuur: Volgens Suetonius (Claudiuss 44) was dit onseker of die keiser tydens sy dinee in die Capitolium deur Halolus, of tuis deur sy vrou met vergiftigde sampioene ('n dis waarvoor hy baie lief was) vermoor is. Die verdere verloop is ook onduidelik - sommige beweer dat hy onmiddellik siek geword het en dwarsdeur die nag erge pyn verduur het voordat die dood teen dagbreek ingetree het. Ander beweer dal hy stuporeus geraak, maar toe dic gif gebraak het, sodat dit nodig was om 'n tweede dosis te gee - sommige beweer met vergiftigde pap, ander vermeld die toediening van 'n gilbevattende dermkliesma. Tacitus (Almales xii. 66-67) skryl dat Claudius tuis deur l lalotus vergiftig is terwyl hy baic dronk was, maar dat akute diarrec ontwikkel het en oënskynlik die gif uit sy liggaam verdryf het. Sy arts, Xenophon (as mede-sameswecrder) het hicrna die misdaad afgerond deur sy keel met 'n vergiltigde veer te streel - kwansuis om braking aan te bring, mar cintlik om doeltreftende vergifliging te bewerkstellig.

\section{Nero (54-68 n.C.)}

Na sy bewindsaanvaarding op ouderdom 18 jaar, hel gilmoord beduidend tocgeneem, veral onder die Romeinse aristokrasie. Wreed en emosioneel onstabiel hel Nero met behulp van die veroordeclde gilmengster, Locusta (wie hy beskerm en selfs gehelp het om 'n skool in die kuns van gilvervaardiging te skep), as gilmoordenalar legendaries geword.'

Die eerste slagoffer was Silanus, populêre goewerneur van Asie, wat bloot uit jaloesie vermoor is met diesellde gif wat in die geval van Claudius gebruik is. Agrippina was primer verantwoordelik hicrvoor (Tacitus, Annales xiii. I; Dio Cassius Ixi. 6.4). Sy stietbroer, Britannicus (14 jaar oud en eie seun van Claudius) was vir Nero ' $n$ bedreiging en is in $\mathbf{5 5}$ om die lewe gebring. Dio Cassius (Ixi. 7.4) vertel dat Nero sy jonger broer eers seksueel verlei het en toe aan tafel vergiftig het. Tacitus (Annales xiii. 14-17) beweer dat Nero jaloers was op Britannicus se mooier stem en klaarblyklike populariteit, en van Locusta gil verkry het wat deur Britannicus se tutors aan hom toegedien is. Hy het toe nie gesterf nie, moontlik omdat die gif as gevolg van diarrec uitgeskei is, of omdat dit te swak was. Locusta is hierna gemartel, maar berei in 'n vertrek langs Nero se slaapkamer 'n nuwe gifmengsel. Tydens 'n ectmal in teenwoordigheid van jong adellikes en hul families is hierdic gif ongesiens aan Britannicus tocgedien. Hy het onmiddellik stuiptrekkings ontwikkel en gesterl. Nero het ongeêrg gesê dat Britannicus aan epilepsie ly, en dikwels sulke toevalle kry. Hy is uitgedra, haastig voorberei en dieselfde aand veras. Suetonius (Nero 33. 3) vertel'n soortgelyke verhaal met meer besonderhede oor hoe die finale gil by herhaling versterk en alan procfdiere gevoer is totdat Nero daarmee tevrede was. Hicrvoor is Locusta (wat deur Claudius ter dood veroordecl is) met 'n keiserlike vrypas uit die gevangenis gelaat.

Nero se moeder, Agrippina, het nou in onguns verval. Pogings om sy guns te herwin, sells deur in die openbaar scksued met hom te flankeer, was onsuksesvol. Nero het ianvanklike pogings om haar te vergittig, laat vaar, omdat, so is beweer, dit bekend was dat sy gerecld effekticwe teengiwwe inneem (Suctonius, Nero 34). Hy het dus sy soldate beveel om halar om die lewe te bring (Tacilus, Annales xiv. 1-3; Dio Cassius Ixii. 13). 'n Orgic van moord is hierna ingelei deur die dood a.g.v. versmoring van Nero se eerste vrou, Oclavia (Tacius, Ammales xiv. 6), en die moord op sy bejalarde lante. Domitia Lepida, on halar besiltings le bekom (Suetonius, Nero 34). Sy was sick met erge hatrollywigheid, en oënskynlik uit belangstelling, het Nero 'n geneesheer beved on vir haar 'n giltige purgecrmiddel voor te skryi.

Burrus, bevelvoerder van die Practoriese Walg, en beperkende faktor in Nero se magspel, het in 62 gesterl. Ily laet gely all in gewas van die keel wal progressiewe asemnood veroorsiak het. maar Tacius (Anncles xiv. 51) en Sueconius (Nero 35.5) beweer dat sy dood veroorsaak is deur gifige keel-en hoesmedisynes wat op Nero se hevel voorgeskryf is. Bencwens gilmoord is groot getalle mense op ander wyses deur Nero tereggestel (Tacilus, Ammales xiv. 50)

Die voedsel en drank van senior senalatslede. walitronder ryk vrygelatenes en vriende van Nero, is vergiltig (Suetonius, Ne'r) 35. 5). Doryphorus en Pallas het in 62 só gesterl ('Ticilus. Annelles xiv. 65). In een stadium hee hy dit oorweeg om die hele Sontalt stelselmatig te vergilig (Suctonius, Nero 43). Die verskyning van komete in $60 \mathrm{cn} 64$ is deur Nero se sterrewiggelatir as voortekens van die dood van belangrike persone uitgele en het gelei lot verdere vervolgings. Twee komplote leen sy lewe is gewelddaldig onderdruk en alle kinders van veroordecldes is geclood deur uithongering of vergiftiging (Suctonius, Nero 36). Nero se lweede vrou, Poppaca, het in 66 gesterl nadat hy halar yelens swangerstap geskop het, malr sommige skrywers vermoed ook hier vergiftiging (Tacilus, Ammales xvi. 5-6)

Aanvanklik mentor en ondersteuner valn Nero. hel die filosoof-stalsman Seneca egter melterlyd van hom vervecem geraak $\mathrm{en}$ is in 65 verdink van ' $n$ sameswering teen die keiser. Op alandrang van Nero het die bejaarde Seneca, in teenwoordigheid van vriende selfmoord gepleeg. Ily en sy vrou het hul polsvale gesny maar nie gesterf nie. Ook die drink van dollekerwel ("hemlock") deur Seneca het nie die dood veroorsaak nic. Hy is hicrna na 'n stoombald gedral walar hy versmoor hel (Tacilus, Annales xv. 60)-62)

Toe sy leer en lyfiag in 68 leen hom in opstand kom, hel Nero besluit om selfmoord te pleeg. en Locusta om 'n vooralial gif gevra, wat in 'n gone kis geplats is. Sy lylhediendes het dit egter verwyder, en op 32-jarige ouderdom sterf Nero nadalt sy sekretaris hom gehelp het om mel 'in blolk sellmoord te plecg (Suctonius, Nero 47-49).

Na Nero se dood, wat 'n cinde gebring het ain die JuliiClaudiese dinastic, is daar 'n bedudende af name in gerapporteerde gifmoorde. 'n Aantal insidente in die volgende twee ecue word voorts bespreek.

\section{Vitellius (69)}

Vitellius se kort bewind is gekenmerk deur groot wreedheid. Onder andere he hy ou vriende en edellui na die hof genooi en hul dan vermoor. Een so 'n persoon he koors ontwikkel en 100 hy om water vra. het die keiser met kwasi-simpallic hom bedien met 'n vergiftigde drankic. 'n Profetes hel voorspel dat Vitellius lank sou lewe mits sy moeder voor hom sterl. Toe sy moeder siek word, het hy haar volgens een oorlewering van honger laat sterl. Ander bronne vermeld dat sy, mocg van die lewe, om gil gevra het en dat Vitellius dit voorsien he (Suelonius, Vitellius 14).

\section{Domitianus (81-96)}

Daar is beweer dat hierdie ongewilde keiser sy baic populere voorganger (en broer) Titus met "sechaas" vergiftig het, malar die inligting is feillik seker apokrief."

Dio Cassius (lxvii. 11.6) skryf dall'n gebruik in hicrdic lyd by moordenaars dwarsdeur dic Romeinse Ryk ontstan het om hul slagoflers met vergiftigde naalde te sleck. Martialis:-t (E:pigram iv. 69) vertel ook van ene Papilus wat daarvan beskuldig 
is dat hy met vergiftigde wyn vier vroue vermoor het.

Die populêre Romeinse goewerneur van Brittanje. Agricola, is in 93 onder verdagle omstandighede op 54-jarige leefiyd oorlede. Dit was bekend dat Domitianus jaloers was op hom, en toc 'n gedrang van holatmptenare en ook genecshere van Rome Agricola tydens sy laaste siekte besoek, het die gerug ontstaan dat die keiser gereël het dat hy vergiltig word. Bewyse hicrvoor is nie gevind nie (Tacitus, ${ }^{25}$ Agricola 43 ).

\section{Hadrianus (117-138)}

Ilierdie bekwame keiser het 'n ongelukkige huwelikslewe gehad, waarskynlik deels weens sy homoseksucle neigings. Toe sy vrou, Sabina, in $\mathbf{1 3 6}$ sterl, is wyd vermoed dat hy haar vergiftig het. Sy aangenome seun, Ccionius Commodus, 'n aantreklike maar ongewilde jong man, het in 138 siek geword en gesterf aan 'n oordosis medisyne. Toe die keiser sell sick word met ernstige edeem, het hy met 'n mes selfmoord probeer pleeg, mar die wapen is van hom verwyder. Hierna het hy druk uitgeoefen op ' $n$ genecsheer om gif aan hom te voorsien, maar eerder as om toe te gee, het die geneesheer homself gedood (Spartianus, ${ }^{26}$ Hadrianus 23-26).

Apuleius het ongeveer in hierdie tyd in sy novelle, Metamorphoses, ${ }^{27}$ die indruk gegee dat gifmoord steeds algemeen voorgekom het (ii. 10.11 en 25-28). Die geneesheer, Galenus (130-210 n.C.) het vertel dat veral die hoë lui in vrees vir gilmoord geleef hel, terwyl die onkunde van sy kollegas grotendeels hiertoc bygedra het. ${ }^{28}$ Galenus was natuurlik bekend daarvoor dat hy baie krities gestaan het tecnoor sy kollegas. ${ }^{29}$

\section{Commodus (180-192)}

Anders as sy vader, Marcus Aurelius, was Commodus as mens en as keiser 'n mislukking. Dic hoof van sy lylwag, Motilenus, is volgens oorlewering deur hom met vergittigde vye vermoor. Eventueel, tydens 'n sameswering het Commodus se gunsteling byvrou, Marcia, hom gif gegee as gevolg waarvan hy lomerig geword, maar daarna begin braak het. Toe dit duidelik word dat hy nie sou sterf nic, is hy deur dic atlect, Narcissus, verwurg (Lampridius, ${ }^{30}$ Commodiss 9).

\section{Caracalla (211-217)}

Sy bewindsaanvaarding het begin met die moord op sy brocr, Geta, wat populêr was met 'n wye aanhang. Hierdie ondersteuners is genadeloos tereggestel, meestal deur die swaard maar ook deur vergiftiging. Spartianus (Caracalla 3 ) beweer dat 20 000 mense so omgekom het.

\section{Heliogabalus (218-222)}

Slegs 14 jaar oud met troonsbestyging, was hy sielkundig abnormaal, as keiser totaal onbevoeg en seksuecl pervert. Toe sy verregaande openbare gedrag tot teenstand lei, het hy sy lyfwag uitgedaag om hom te vergiftig, of met die swaard tc dood. Vier jaar na bewindsaanvaarding, is hy in sy latrine deur dic Practoriese Wag gedood (Lampridius, Heliogabalıs 13).

\section{GIFSTOWWE AAN DIE ROMEINE BEKEND}

'n Volledige beoordeling van gifstowwe aan die Romeine bekend (hul oorsprong, beskikbaarheid en werking), is die onderwerp van 'n ander studie. ${ }^{31}$ Uit die werke van veral Dioscorides, Scribonius Largus, Nicander, Plinius en Galenus, asook oorsigarlikels deur o.a. Horstmanshoff, ${ }^{32}$ Kaufman ${ }^{33}$ en Smith' kan die volgende bekendste gifstowwe gelys word:

\section{(i) Plantaardig:}

Nastergal (atropa belladonna), bilsckruid (hyoscyamos niger), m.dndragora (solanaceae) en gifappel (datur't ) bevat belladonna- alkalojede wal onder andere drö̈ mond. rusteloosheid, delirium, manie en koma mag veroorsaak. Dollekerwel (conimm maculatum, "hemlock") se piridien-alkalö̈ede en koniin veroorsaak progressiewe verlamming. Monnikskap) (aconirmm napellus) bevat alkaloïede wat soos die veratrum folisiene van onder andere nieskruid (hellebortes niger, "hellebore") oorwegend kardiotoksies en verlammend inwerk. llerlskrokus (colchicum culumnalis, "meadow saffron") se kolgisien hel "n dergelike elfek en veroorsalk ook braking en cliarrec. Opium uil dic opiumpoppic (papaver somniferam) hel lomerigheid. psigiese alwykings en koma veroorsaak. Dic laksusplant (kasus baceala, "yew") bevat veral pseudo-alkaloïede wall dermkanaialsimptome en verlamming aanbring. 'n Verskeidenheid giftige paddastoele (onder andere amanita phalloides en a. musearia) en boomfungi was bekend. ${ }^{4.35 .15}$ Spiespunte is soms in 'n gilitge strignosverbinding gedoop (Plinius xxi. 177), malt van strignien mak antieke skrywers geen melding nic.

\section{(ii) Diere-oorsprong}

'n Verskeidenheid gillige slange (bv. vipera. aspis. dipsas en hidri), spinnekoppe en skerpioene is erken. Salamanders, sckere akkedisse en muise is as giftig beskou. Die bloed van bulle. slange, bokkapaters en sekere paddas ("toads"), en die vleis van sekere seediere, bv. lagos en lepus marimus ("scehaas" - lans aan ons onbekend) en sekere muishonde is as gillig beskou. Ekstraktc van insektc soos bupestris (langbeeninsek, lans onbekend), denne-ruspes en veral die Spalanse vlieg (kantaridien) is as giftig vir die mens beskryf. Laasgenoemde, wat irritesend op die vel ingewerk het en onder andere ernstige laerurinewegbeskadiging kon veroorsaak, is ook as afrodisiak gebruik.

\section{(iii) Minerale}

Hierdie gifstowwe was wairskynlik in die Romeinse lye min gebruik. Daar word wel melding gemaak van giftige loodverbindings, soos karnisict (loodkarbonaat), willood (loodasetat. "cerussa") en loodglit (loodprotoksied, "litharge"). Gilitge arseenverbindings in lood-, goud- en silwermyne is als gevalar vir myners erken; "realgar" of "sandarach" was arsecnsullied (in geel of rooi vorm) en is veral as kleurstow we gebruik (Plinius xxxiv.54-55; Strabo ${ }^{36}$ xii.3.39). Giltige swacldampe in myne opgemerk was waarskynlik arseensullied. Kwiksilwerverbindings is deur Livius (xxxiv.54) in ongesonde myne geïdentifiseer, en kwikamalgaam is in die juweliershedryl gebruik. Sommige antimoon- en koperverbindings is as giftig beskryf, terwyl Plinius (xxix.100) verwys na 'n pylgif vall onbekende aard.

\section{BESPREKING}

Kaufman ${ }^{33}$ beweer dat die woord venenum ("venom") afgelei is van Venus en oorspronklik ' $n$ liefdesdrank beteken het. Dil is oorspronklik wyd gebruik om die konsepte van medikant, gil. towerdrank of aborsiemiddel te dek, en die toepassing is gekwalifiseer deur die byvoeglike naamwoord bommm (ten goede) of malum (ten kwade)

\subsection{Bronne}

Verwysings na vergiftiging is volop in die Romeinse literatuur. en 'n wye verskeidenheid bronne is geraadplecg. Waar meer as een outeur ' $n$ insident beskryf hel (bv. die dood van Claudius), is al die weergawes gegee en is daar nie groot dispariteite nie, wat historiese juistheid meer waarskynlik maak. Vir dic vroeë geskiedenis van Rome het ons hoofsaaklik vir Livius as bron. met die gevolg dat die historiese juistheid van sy beskrywings nie in al die gevalle wat bespreek is, gekontroleer kon word nie. 
Livius sell het egter krities ongegaan met die enkele (nou verlore) bronne wat tol sy beskikking was, en was wel bewus van die onbetroubaarheid van dic vroeë geskiedskrywing. Ily het nie geskroom om bygelowige praktyke en volksherinneringe wat 'n kern van waarheid beval het, weer te gee nie, maar het dit mel 'n gesonde knippie skeptisisme benader. ${ }^{37}$ Die ander belangrike geskiedskrywer wat as bron gebruik is vir dic periode onder bespreking, is Tacitus, wat bekend was vir sy bevooroordeeldheid jeens Tiberius - so bv, was die "gifmoord" op Germanicus 'n ooglopende poging om dić keiser op indirekte wyse in diskrediet te bring (sien p. 8). Ook Livia se aandecl in die dood van Augustus se kleinscuns en van Augustus self is moeilik geloolbaar, malar hier word Tacitus - soos in die ander insidente wat bespreek is - deur ander bronne gesteun wat die geloofwaardigheid van die beskrywing verhoog. Suetonius het as biograaf allerlei interessante anckdoles weergegee watrvan die oorsprong en historiese juistheid ongelukkig moeilik vasstelbalr is. Vir die laat Keisertyd het ons slegs die sg. Scriptores Historiac Augustac (Lampridius en Spartianus ressorteer hicronder), 'n versameling skrywers wat berug was vir hul onbetroubalarheid; dic enkele insidente wat bespreck word, is egter nie kontensicus nic.

\subsection{Moord en selfmoord}

Vergiftiging behels moord sowel as selfmoord. Dit is has onmoontlik om te bepaal of moord of selfmoord in Romeinse tye meer dikwels voorgekom het as vandag, ${ }^{33}$ malar vergiftiging as misdaad was veral onder die hoëlui en rykes 'n aansienlike probleem. Tacilus gebruik die woord scelus (misdaad) dikwels om spesifiek gifmoord aan te dui. ${ }^{32}$ Dic beskikbaarheid van vuurwapens is moontlik 'n rede vir minder gilmoorde in moderne tye. ${ }^{33}$

Dit is egter opvallend dat gil by voorkeur die moordwapen was wat deur vroue gebruik is - moontlik omdat dit nie fisieke geweld behels nie en moeilik herken- of onderskeibaar is van natuurlike oorsake, en dic taak van dic materfamilias as kosbereider en verpleër van die sickes in die lamilie vir die vrou talryke geleenthede gebied het.

\subsection{Identifisering van gifstowwe}

In die era voordal toksikologiese tegnieke dit moonllik gemaak het om die voorkoms van vergiftiging wetenskaplik te bevestig, het daar' 'n aura van mistick hieraan gekleef.' In tye van ontbering veral, is gerugte van vergiftiging maklik aangegryp as oorsaak van onverklaarbare mortaliteit - en veral in bygelowige gemeenskappe kon gifdeskundiges magsposisies bekom of ambisieuse skemas realiseer deur massa-vrees te bewerkstellig. Dit is dus waarskynlik dat nic alle bovernelde episodes in dic Romeinse cra aan doelbewuste vergiftiging toegeskryf kan word nic, en dat mortaliteit tydens epidemies soos dié van 331 v.C. inderdaad suiwer aan siekte en nie gif nie, le wyte was. Livius (viii. 18) was by voorbeeld nie daarvan oorluig dat die beweerde massavergiftigings van 331 v.C. ten lye van 'n pestilensie (cn waarvoor 170 vroue tereggestel is), wel bewys is nie. En dan is dit duidelik dat sekere nadoodse veranderinge wat as aanduidings van vergiftiging beskou is, glad nic daarmec verband hou nic. Hieronder tel byvoorbeeld donker verkleuring van die lyk se vel (Juvenalis, Satire i. 73-76; Dio Cassius Ixi. 7.4), en vertraagde verrolting en swelsel (Seneca, Controversiae vi. 506). Dio Cassius (Ixi. 7.4) vertel dat Nero gereêl het dat dic vermoorde Britannicus se lyk mel wil gipspoeier bedek word om die "kenmerkende" donker velverkleuring te bedek - maar dat ' $n$ reènbui in die Forum die gips afgespoel het en omstanders dus die "bewys" van vergiftiging gesien hel.

Horstmanshof ${ }^{32}$ maak 'n goeie saak uil dat monnikskap (akonitum) Britannicus se akute dool veroorsalak hel. Smith' meen dat sianied gebruik is - 'n besonder potente gif wall ö̈nskynlik teen 400 v.C. reeds deur die Egiplenare berei is. Dalar is egter geen getuienis in Romeinse literaltutur clat sianied (uil pitvrugte berci) ain hul bekend was nic. Anders ans in die Middelecue en later, toc arseen die populêre gil wals,' is dic doelbewuste gebruik daarvan as gil in Romeinse lye nie gedokumenteer nie. ${ }^{23}$ Die giftige aard van arseenverbindings in sckere myne is deur Plinius (xxxiv. 55) erken, malar dit word slegs as kleurstof benut. Dat dit wel als sulks benut matat nic beskryf is nic, bly natuurlik moontlik.' Strignien het eer's in dic 17 de eeu in Europa bekend geraak." Dit is inderdalad waarskynlik dat erkende gifbereiders soos Locusta. Martina en Canidia, preparate voorberei het wat wit 'n mengsel vall gifstowwe bestaan het. Hierdie persone het vall procldiere gebruik gemaak om die toksisiteil van hul mengsels te hepial (Suctonius, Nero 33.3). In anticke tye is sterk geglo an die doeltreffendheid van teëgiwwe soos Mithridatum en Teriah. maar vandag aanvaar ons dat hierdie preparate heeltemal oneffekticl was. ${ }^{1.2 \mathrm{x}}$

In sy uitstekende oorsig van vergiftiging in die lyd van Nero beweer Horstmansholl't dat vergitiging ook dikwels die gevolg was van wangebruik van medikamente deur antse en aptekers wie se bedoelings suiwer, malar kennis gebrekkig wass. Ons weel ook van geneshere, soos Xenophon (Tacilus, Amnales xii. 6667), cn andere (Suctonius, Nero 34) wat an moord medepligtig was - lerwyl die geneesheer van Hadrianus eerder selfmoord gepleeg hel as om gil aan die keiser Ic gee (Sparlianus. Hadrianus 23-26). Gif is gewoonlik by die slagolfer se voedsel of drank gevoeg, matr is soms as medisyne angebied (Suetonius, Nero 34; Tacitus, Amnales xiv. 51), per kliesmal gegee (Suetonius, Claudius 44) of aan nalalde gesmeer walarmee slagoffers gesteek is (Dio Cassius Ixvii. 11.6). Tacilus (Amnales xii. 66-67) beweer dat Xenophon Claudius se moord algerond hel deur 'n vergitigde veer in sy keel te vryl.'

Omdat historici slegs in enkele gevalle simptome en besonderhede verskal van hoe slagoffers gesterf hel, is dit hykans onmoontlik om die verantwoordelike gifstowwe te probect bepaal. In sekere gevalle word die gif egler spesilick genoem Canidia het dollekerwel in heuning gebruik (Horatius. Satire ii. 1.56); Catuvolcus pleeg mel laksus-sap selimoord; ${ }^{15}$ Senecal drink dollekerwel (Tacitus, Annales xv. 60-62); Oviclius heskryl monnikskap as "slielma se gif" en Juvenalis (Sarire i. 58) verwys ook na die gebruik van hierdie gif. Claudius sterl ná sampioen-inname - maar hier word verwys na vergifiggde sampioene eerder as giflige sampioene (Tacitus, Annales xiii. 1) sodat ons onkundig bly oor die spesilieke alard van die gil. Commodus sterl aan vergiftigde vye (Lampridius, Commmolus 9) - weereens is die gil nie identifiseerbatar nic. Inderdad sal die presiese aard van gifstow we wat in die Romeinse era gebruik is, waarskynlik by dic oorgrote meerderheid van gifmoorde alan ons bekend, spekulaticf bly.

\subsection{Vergiftiging en die sosio-politiese omstandighede}

Dit val op dat daar 'n groter aantal sterftes as gevolg van gif in sckere periodes van die Romeinse geskiedenis was as in ander: Ecn van die redes hiervoor is ongetwyleld die heersende sosiopolitiese omstandighede. So bv. vind ons dal grootskalalse vergiftiging of aanklagle daarvan in vroeě Rome saamgeval hel mel krisisomstandighede soos oorloë. epidemies of salmeswerings - bygelowigheid van 'n minder ont wikkelde bevolking wat sondebokke gesock hel, sou wel hier 'n bepalende faktor gewees hel. Vanaf die Iste eeu v.C. kom massa-vergiftigings nie meer voor nie, maar wel talle individuele gevalle wall toeneem nader aan die eeuwending. Dil was eglel veral tyclens 
die bewind van die Julii-Claudiese keisers in die vroeg 1 sie ecu n.C. toe magstrewes en politicke intriges hoogly gevier het, dat gifmoorde en selfmoorde m.b.v. gif aan die orde van die dag was. Hierdie periode is baic goed gedokumentecr, en Tacitus en Suetonius se treffende beskrywings van die moorde op vooraanstaande persone soos Germanicus en Britannicus het 'n onuitwisbare indruk gelaat. In die 2 de eeu n.C., die bloeitydperk van die Romeinse Keiserryk, weet ons van baie min sterftes a.g.v. gif - dit kan wees omdat dié periode minder goed gedokumenteer is as die lste ecu v.C., of omdat dic spanning en vrees wat in dic vorige twee ceuc aanleiding gegec hel tot soveel selfmoorde en gifmoorde, nou eindelik plek gemaak het vir rustiger lewensomstandighede onder die bekwame heerskappy van die keisers van die 2 de ecu n.C.

\section{SUMMARY}

The incidence and nature of poisoning in ancient Rome (6 $6^{\text {II }} \mathrm{cen}$ tury $\mathrm{BC}$ to $3^{\text {ral }}$ century AD) was studied.

The first recorded incident was in $331 \mathrm{BC}$, at the time when Rome suffered a severe epidemic and 170 women were tried and convicted for mass poisoning of the populace. A similar incident occurred during an epidemic in 184-180 BC when 3000 people were executed. Historians subsequently recorded a growing incidence of poisoning which reached an alarming peak during the reign of the Julio-Claudian emperors, and of Nero in particular. During the I $^{\text {st }}$ century AD the satirist Juvenal described the moral decay of the elite, and in his satires claimed that poisoning for personal benefit had become a status symbol. Suicide by poisoning was not common, but Pliny the Elder defended euthanasia by poisoning in the elderly, when so desired. In a culture of high superstition when scientific ignorance made the detection of poisoning virtually impossible, it was very difficult to prove incidents of poisoning. It is likely that many poisoners went unpunished, while innocent citizens were wrongly condemned. Inadvertent poisoning through medication prescribed by ignorant professionals, was probably common.

Incidents of probable poisoning described, include the mass suicide of the surrendering Capuans in $211 \mathrm{BC}$; the tragic death of the Numidian qucen, Sophonisba; and death by poisoning of two consuls in $154 \mathrm{BC}$. At the end of the $2^{\mathrm{mll}}$ century BC Rome had a special court dedicated to poison trials, and in $80 \mathrm{BC}$ Sulla promulgated strict laws against poisoning and the handling of poisons. Cicero's court speeches confirm the high incidence of murder by poisoning, and it is also probable that Cleopatra committed suicide using poison in $30 \mathrm{BC}$.

The Julio-Claudian dynasty $(27 \mathrm{BC}-68 \mathrm{AD})$ in the early days of the Roman Empire was infamous for poisoning. Augustus' wife, Livia, probably poisoned two of her step-grandchildren in order to ensure the succession of her son Tiberius, and there was even a rumour that she had eventually poisoned her husband. In one of Horace's Salires we read about the professional poisoner, Canidia, who with Martina and Locusta became the infamous trio of women poisoners in Roman times. Tiberius was certainly innocent of the suspected murder of his popular nephew, Gcrmanicus, and his son, Drusus, but death by poisoning was rife in his time. Gaius (Caligula), his unstable successor, had a collection of poisons with which he eliminated many of his underlings. Claudius probably suffered from a form of cerebral palsy, but was surprisingly efficient as a ruler and was not personally involved in poisoning. It is probable, though, that he was fatally poisoned by his second wife, Agrippina, the mother of Nero. He became infamous for murdering a large number of his subjects, including Silanus (governor of Asia); his half-brother, Britannicus, his aunt Domitia, Burrus, prefect of the Praetorian Guard; and many lesser friends and slaves.
According to the biographer Suetonius he even considered systematically poisoning the entire Senale.

Episodes of poisoning during the reign of subsecfuent emperors, like Vitellius, Domitian. Hadrian, Commodus, Caracalla and Alexander Severus, are reviewed.

Our knowledge of poisons available during Roman times emanates from the writings of Dioscorides, Scribonius Largus. Nicander, Pliny the Elder and Galen. Poisons were of vegetable, animal and mineral origin. Animal poisons were not well investigated in ancient times, and included camtharadine as well as unlikely poisons related to bull's blood, toitds, salamanders and marine animals; poisonous insects, snakes, spiders and scorpions were known but very rarely used in homicide. Mineral poisons, e.g. salts of Iead, mercury, copper, arsenic and antinomy were known but virtually never used. Fumes in lead, silver and gold mines were recognized as toxic.

Vegetable poisons were best known and most lrecuenly used. They included plants with belladonna alkaloids, c.g. henbane, datura, deadly nightshade and mandrake, aconite from monk's hood, hemlock, hellcbore, colchicum (from aulumn crocus), yew extract, and opium. Strychnine was unknown to the Romans, and there is no evidence that cyanicle was extracted from kernels of certain fruits.

Historians rarely mentioned specilic poisons when descrihing incidents of poisoning. Horace, however. does mention hemlock in honey as the poisons favoured by Canidia, and we know that Seneca drank hemlock; Ovid calls aconite the "mother-inlaw's poison"; the British king, Catuvolcus, commilted suicide with yew-extract; Claudius died alter cating poisoned mushrooms (a strong case is made out that aconitc was used. and that this was also Nero's favourite poison). The ancients apparently could not distinguish confidently between edible and toxic mushrooms. Professional poisoners often tested the potency of their mixtures (probably containing multiple toxins) on animals, slaves or convicts.

In conclusion socio-political circumstances were considered. It is clear that mass poisoning in early times occurred more frequently during stressful periods like wars, epidemics. elc. From the $1^{\text {sl }}$ century $\mathrm{BC}$ onwards individual cases of poisoning increased, reaching a peak during the reign of the Julio-Claudian emperors, when ambition and political intrigue were the order of the day. In the $2^{\text {inl }}$ century $A D$, the heyday of the Roman Empire, when the tensions and fear of the previous iwo centuries made way for peace and quiet, very lew deaths duc 10 poisoning were recorded.

\section{LITERATUURVERWYSINGS}

I. Smith, S. (1952). Poisons and poisoners through the ages, Medicolegal Journal, 20, 153-167.

2. Retief, F.P., Cillicrs, L. (1999). Dood van Klcopara. Cieneeskunde. 4(I), 8-II.

3. Bloch, H. (1987). Poisons and poisoning: implications of pliysicians with man and nations, Jourmal of Nol. Med. Associ, 79(7). $761-763$.

4. Pliny [Plinius die Oucre]. (1940-1963). Nanural History. Volumes 1-X. Transl. by H. Rackham et al. Locb Classical Library (Cambridge MA: Harvard University Press).

5. Juvenal [Juvenalis]. (1930). Jllenal and Persias. Transl. by G.G.Ramsay. Loeb Classical Library (Cambridge MA: Harvard University Press).

6. Livy [Livius]. (1922-1959). History of Rome and Summaries. Volumes l-XIV. Transl. by B.O.Fostel el al. Loeb Classical Library (Cambridge MA: Harvard University Press).

7. Polybius. (1922-1927). The Histories, Volumes I-VI. Thassl, by W.R.Paton. Loeb Classical Library (Cambridge MA: Harvard University Press)

8. Plutarch [Plutarchus]. (1914-1926). The Paral/el Lites, Volumes I- 
XI. Transl. by B.Perrin. Loel) Classical Library (Cambriclge MA Harvard University Press).

9. Quintilian [Quintilianus]. (1920-1922). Truining of an orator, Volumes I-IV. Transl by H.E.Butler. Loeb Classical Library (Cambridge MA: Harvard University Press).

10. Badian. E. (1962). Forschungsbericht. From the Gracehi to Sulla. 1940-1959, Historia, II.1, 197-245.

11. Scullard, H.H. (1982). From the Gracedi fo Nero. A history of Rome from I33 BC $10 A D$ O8 (London: Methuen).

12. Cicero. (1979). Orations. Vol, IX. Pro Cluentio el al. Transl. by H.G.Hodge. Locb Classical Library (Cambridge MA: Harvard Universily Press).

13. Cicero. (1938). Oratiom.s. Vol. XV. Philippics. Transl. by W.C.A.Ker Loeb Classical Library (Cambridge MA: Harvard University Press).

14. Cicero. (1976). Orations. Vol. X. In Carilinam I-IV. Locb Classical Library (Cambridge MA: Harvard Universily Press).

15. Fröhune, D., Pländer, H.J. (1983). Colour atlas of poisomous plamts (Wolle Science Book).

16. Tacitus. (1956-1996). The Ammals of Imperial Rome. Transl. by R Graves (Penguin Classies).

17. Dio Cassius. (1914-1927), Rommon History, Volumes I-IX. Transl by E.Cary. Loeb Classical Library (Cambridge MA: Harvard University Press).

18. Horace (Horatus), (1932). Sarires, Epistles, Ars Poetica. Transl. by H.R.Fatirclough. Loeb Classical Library (Cambridge MA Harvard Universily Press).

19. Suctonius. (1960). The melse Cuesars. Transl. by R.Graves (Penguin Classics)

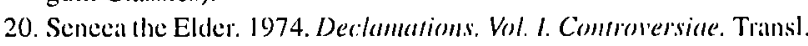
by M.Winterbonom. Loeb Classical Library (Cambridge MA Harvard University Press).

21. Levick, B. (1990). Clandius (London: B. Y.Baltsford Lid).

22. Josephus. (1959-1967). The Jewish/ War. Transl. by G.A. Williannson (Penguin Classies).
23. Thompson, C.J.S. (1931). Poisons and poisoning (New York: McMillan \& Co).

24. Martial [Martialis]. (1993). Spectucles. Vol I. Books 1.V. Tranns by D.R.Shackleton Bailey. Locb Classical Library (Cambridge MA: Harvard University Press).

25. Tacilus. (1946). Vol. I. Agricola. Ciermania. Didelogue on oramory: Trausl, by M.Huton. Loeb Classical Library (Cambridge MA: Harvalrd University Press).

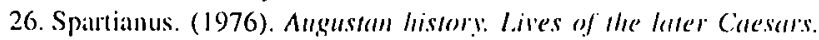
Transl. by A.Birley (Penguin Classics).

27. Apulcius. (1989). Metamerphosses. Vol.II. Transl. by J.A.Hanson Loeb Classical Library (Canbridge MA: Harvand University Press).

28. Nutton, $V$. (1985). The drug trade in antiquily. Iommal of Roryal Society of Medicine, 78, 138-145.

29. Christic, R.V. (1987). Galen on Erasistratus, Perspectivess in Biology' and Medicine, 30, 440-449

30. Lampridius. (1995). Chromicle of the Romun Fimpire. Transl. by C. Scaure (London: Thames \& Hudson).

31. Retief, F.P., Cilliers, L. (2000). On poisons and the drug triele in ancient Rome. Voorgelè vir keuring an Soncial Hisiory of Medicine.

32. Horstmansholf, H.F.J. (1992). Gemeen goed. lampas. 25(1), 3255.

33. Kaufman, D. B. (1932). Poisons and poisoning among the Romauns, Classical Philology; 27, 156-167.

34. Watt, J.M. \& Breyer-Brandwijk, M.C. ( 962). Medicinal amd poisonoms phants of Somth and Eastern Africa (Livingsione Lid).

35. Munday, J. (1988). Poisomous plamts in Somul African gerrdens and parks. (Delta Books).

36. Strabo. (1917-1932). Geography: Volumes I-VIII. Transl. by H.L.Jones. Locb Classical Library (Cambridge MA: llarvard University Press).

37. Laistne;, M.L.W. (1963). The greater Roman hisuriams (Berkeley and Los Angeles: University of California Press) 